\title{
The role of natural factors (part 2): Indian summer monsoon in climate change period-observation and CMIP5 models
}

\author{
Indrani Roy ${ }^{1,2}$ (D) R. H. Kripalani ${ }^{3}$
}

Received: 24 April 2018 / Accepted: 7 April 2019/Published online: 17 June 2019

(C) The Author(s) 2019

\begin{abstract}
This study discusses the role of natural factors and related teleconnections for Indian summer monsoon (ISM) with a special emphasis on later two decades of the last century. The combined influence of the sun and volcanos on ISM is examined using observational data as well as CMIP5 model outputs. Possible mechanisms relating to a disruption of the usual ENSO-ISM teleconnection for those decades are explored. Observation suggested that the regional Hadley circulation, via the NAO in the northern hemisphere and Indian Ocean Dipole in the southern hemisphere, may have a role in the change in ISM behaviour. Such features though captured well in the observation are shown missing in models. Additionally, it indicates that differences among models mainly originate in a regional level, which could be due to inconsistency in representing regional teleconnection features. Interestingly, all models perform reasonably well in terms of global thermodynamic scaling arguments. The overall study underpins important areas, where natural factors influence regional climate, but models miss out and suggest discrepancies among each other. Such knowledge has major implications in regional as well as global scale. The modelling community will also greatly benefit by an improved representation of ENSO and ISM in models.
\end{abstract}

\section{Introduction}

Indian summer monsoon (ISM) provides the major share of total annual rainfall of the country and has enormous impacts on the Indian economy. Being one of the most populated countries in the world, its variations influence the global economy as well. Moreover, the ISM system dominates the northern summer Hadley circulation (Trenberth et al. 2002) and hence has an important contribution to the global atmospheric circulation.

The El Niño Southern Oscillation (ENSO) is one of the most important tropospheric modes of variability that affects

R. H. Kripalani is retired Senior Scientist, Indian Institute of Tropical Meteorology (IITM), Pune, India.

Indrani Roy

indrani.roy@ucl.ac.uk; indrani_r@hotmail.com

R. H. Kripalani

krip@tropmet.res.in

1 University of Exeter, Exeter, UK

2 University College London (UCL), IRDR, London, UK

3 Indian Institute of Tropical Meteorology, Padamji Paradise, Bhawani Peth, Pune 411002, India different regions around the globe through teleconnection. Various forms of ENSO have been discussed in recent research; those are based on spatial sea surface temperature (SST) patterns around the Tropical Pacific. The first type suggests a strong variability around the East Pacific (EP), known as EP type or Canonical ENSO, and the second one is dominated by variability around Central Pacific (CP), known as $\mathrm{CP}$ type or Modoki ENSO (Larkin and Harrison 2005; Trenberth et al. 2002; Ashok et al. 2007; Kug et al. 2009; Hill et al. 2009). There are also differences in global and local influences between these two ENSO (India: Roy and Tedeschi 2016; Roy et al. 2017; Australia: Cai and Cowan 2009; Global: Weng et al. 2007; Ashok et al. 2007; Roy et al. 2018). Recent studies (Kao and Yu 2009; Kao and Yu 2009; Roy and Kriplani 2018) compared these two forms of ENSO and explored the differences regarding their evolution, structure and mechanism.

The ENSO can influence seasonal precipitation in various regions of the globe, and Indian summer monsoon (ISM) is one of the most crucial one (e.g. Maity and Kumar 2006; Kripalani and Kulkarni 1997; Roy 2017). It was shown that El Niño (EN) years experience less rain whereas La Niña (LN), more rainfall. Interestingly, ISM and ENSO suggest a weaker correlation during last few decades of the twentieth century and experience a normal level of rainfall despite EN years (Kumar et al. 1999; Ashok et al. 2001). Ashok et al. (2001) showed that Indian Ocean Dipole (IOD) and ENSO 
have complementarily affected the ISM during a similar period. They revealed that when the correlation between ENSO and ISM is weaker, the relationship between IOD and ISM is strengthened and vice versa. Roy and Collins (2015) using observational data of sea level pressure (SLP) showed that the Southern Oscillation (SO) pattern as captured in the ENSO indicates major changes around Australia in the latter half of the last century. Interestingly, Australia (Darwin), one lobe of the SO seesaw is also coincidentally one edge of IOD. Another strong influence on ISM comes from the North Atlantic Oscillation (NAO) (Liu and Yanai 2001). When the relationship between the temperature of west Eurasia and ISM is stronger, over the same period, the relationship between the ISM and ENSO has weakened (Chang et al. 2001). According to them, as the ENSO ISM teleconnection became weaker, the possibility for the NAO to influence the ISM through the above mechanism has enhanced. The connection between IOD, ISM and NAO are in favour of a linkage that involves regional Hadley circulation and ITCZ and follows the mechanism of Gill (1980). In the location of Central North East (CNE) regions of India around ITCZ, the coupling mechanism of ocean and atmosphere via the Hadley and Walker circulation could be communicated strongly (Gill 1980).

The ENSO-monsoon connection showed a common point of deviation at around the 1970s. The correspondence indicated an enhancement for North America, western North Pacific, Northern African and South American summer monsoons, whereas, a weakening for the ISM, (Yim et al. 2013). Though in the late 1990s, there was a recovery for all cases. Huang et al. (2013) in a recent study discussed such changing patterns of monsoon under warming situation. A decreasing trend in precipitation around India, under global warming condition, was detected in observations (Ramanathan et al. 2005; Chung and Ramanathan 2006 and Goswami et al. 2006) that contradicts the proposed hypothesis based on thermodynamic scaling arguments (Held and Soden 2006; Vecchi and Soden 2007). Thermodynamic scaling argument suggests more rainfall in a warm environment. In climate change scenario, the direction of anomalous change in circulation fields (Hadley as well as Walker circulation) and their relative strength, mainly in the CNE region of India require extra attention (Bollasina et al. 2011; Roy 2018c). Observation suggests that over a similar period, the nature of ENSO has also changed. Since the 1970s, ENSO Modoki became more frequent and persistent (Yeh et al. 2009; Ashok and Yamagata 2009). McPhaden et al. (2011) indicated that the rise in Modoki ENSO during the latter decades of the twentieth century could also partly be due to decadal variability.

To understand the role of natural factors on the variability of ISM, it is important to address the influence from both the sun and major volcanos. The Sun is the primary source of energy for our climate. Decadal signature of changes in solar variability is detected in various atmospheric and oceanic fields (Haigh et al. 2005; Meehl et al. 2009; Brönnimann et al. 2006; Lee et al. 2009; Zhang and McPhaden 2006; Lorenzo et al. 2010). Two major volcanos erupted during later decades of the last century (1981 and 1992), which were strongest ever in the record of past 150 years. Contrary to the earlier eruptions, those two even coincided with active phases of high solar cycles. The influence of explosive volcanos on the ENSO phase was discussed in various observational (Adams et al. 2003; EmileGeay et al. 2008) as well as modelling (Stenchikov et al. 2009; Ohba et al. 2013) experiments, which univocally suggested a significant rise in the likelihood of El Niño events. Ohba et al. (2013) using a Model for Interdisciplinary Research on Climate (MIROC5) suggested about excitation of the anomalous Pacific westerly for explosive volcanos which subsequently causes an increase in the probability of El Niño. Their model result indicates that explosive volcanos during the El Niño phase contribute to the duration of El Niño, whereas the same during La Niña shorten its period counteracting to its duration. Using a Geophysical Fluid Dynamics Laboratory (GFDL) CM2.1 model, a similar response is also noticed by Stenchikov et al. (2009). They discussed that such effect on El Niño arises due to the amplification by the air-sea coupled feedback. Without major volcanos in recent decades, the ENSO cycle is likely to show equal tendencies for warm as well as cold phases and also favours the recovery of that drying ISM trend, following usual ENSO-ISM anti-correlation. ISM precipitation has likely increased over the last decade, after reversing the drying trend that happened from the mid of the 1970s to the mid of 1990 s (IPCC 2013).

Roy (2017) and Turner and Annamalai (2012) used CMIP3 and CMIP5 model simulations respectively to examine/ compare ISM precipitation and ENSO with observation. The authors elaborately discussed various issues why models failed to match observations. All those studies indicated further understanding and model improvements are necessary to improve ISM prediction skill. Turner and Annamalai (2012) noted that the correlation between ISM and ENSO wanes and waxes to a certain degree in models which are decadal in nature. But, in the phase among the realisations, there is little consistency in models that points towards a lack of predictability of the decadal modulation of the ENSO-monsoon connection (Turner and Annamalai 2012). Using a model, Cash et al. (2017) discussed that for observed fluctuations, sampling variability can also be a responsible factor. In terms of mechanisms relating to disagreement among observation and model results, various studies addressed it from various angles; those include aerosol-based changes (e.g. Bollasina et al. 2011), circulation-based changes (e.g. Annamalai et al. 2013), and sea surface temperatures in the Indo-Pacific (e.g. Roxy et al. 2015). Systematic errors are also present in the ISM simulations and all these caveats should be addressed while interpreting diagnostics of ISM and its response in the global warming scenario (Annamalai et al. 2007). 
This study focuses on some of those important issues as mentioned. This paper is structured as follows. Section 2 describes methodology and data and results are discussed in section 3. In the beginning, we focus on results of MLR analyses. Later, it covers the so-called 'climate change period' and its relevance to the changing pattern of ISM. It discusses the spatial pattern as well as the temporal behaviour of various climate parameters and indices and compared observation with CMIP5 model results. Section 4 mentions conclusions. Overall, this study will discuss different teleconnections with the ISM, giving special emphasis on the so-called 'climate change' period. It also discusses areas where models agree with each other in general but fails to comply in various aspects of the regional pattern.

\section{Methodology and data}

In the initial section, the method of multiple linear regression (MLR) analysis with AR (1) noise model is used. It is developed by Myles Allen, the University of Oxford, and widely used in various climate studies (Roy and Haigh 2010, 2011, 2012; Roy 2014, 2018a, b). In this methodology, with the components of variability, noise coefficients are calculated simultaneously. Finally, the levels of significance are calculated, using Student's $t$ test.

Variables and climate indices used in the MLR are sea level pressure (SLP), a longer term linear trend (to represent anthropogenic climate change), monthly sunspot number (SSN), Niño 3.4 (for ENSO) and stratospheric aerosol optical depth (AOD, to represent volcanic eruptions). For SLP, the in-filled HadSLP2 dataset, available as monthly means from 1850 to 2004 , is used. ${ }^{1}$ It has been updated up to 2012 using HadSLP2r_lowvar data. ${ }^{2}$ Monthly SSN is used to represent solar cyclic variability. ${ }^{3}$ In the regression, AOD represents volcanic eruptions and collected from Sato et al. (1993). ${ }^{4}$ It is available up to 1999 and then extended to 2005 with near zero value. It can also be obtained from KNMI Climate Explorer. ${ }^{5}$ For the ENSO, Niño 3.4 index is used ${ }^{5}$ obtained from Kaplan et al. (1998).

For trend analysis, the various indices we used are the NAO, Southern Annular Mode (SAM), IOD, Niño temperatures $(1+2$ and 3.4), EP and CP ENSO, SLP Darwin and Tahiti and regional ISM precipitation. For NAO, DJF value is considered and for the rest, a seasonal value of JJA is used. This is because studies (Liu and Yanai 2001, Xavier et al.

\footnotetext{
$\overline{1}$ Available at URL http://www.metoffice.gov.uk/hadobs/hadslp2

${ }^{2}$ Available at URL http://www.metoffice.gov.uk/hadobs/hadslp2/data /down load.html

${ }^{3}$ Available at URL http://ftp.ngdc.noaa.gov/STP/SOLAR DATA/ SUNSPOT NUMBERS/INTERNATIONAL/monthly/MONTHLY.PLT

${ }^{4} \mathrm{https}$ //data.giss.nasa.gov/modelforce/strataer/tau line.txt

${ }^{5}$ http://climexp.knmi.nl
}

2007) suggested winter NAO and Eurasian temperature has impacts on ISM (JJA). The discriminates for different trend periods are used, e.g. 1970, 1976 or 1957, which are based on following justifications: the 1970s is an abrupt drop in SSTs (Thompson et al. 2010); 1976 is the well-known Pacific regime shift (Miller et al. 1994); 1957 could be justified instrumentally as it is termed as International Geophysical Year (IGY) and from that period many other observations started. Other reasons for justification are also mentioned in the text.

The monthly EP and CP indices are calculated ( $\mathrm{Yu}$ and Kim 2010; Kao and Yu 2009) from the Extended Reconstructed Sea Surface Temperature (ERSST) dataset (Smith and Reynolds, 2004) that used 1971-2000 climatology and available from 1948 to 2014 in the relevant web links. ${ }^{6,7}$ Yu and Kim (2010) and Kao and Yu (2009) used a regressionEOF technique to identify the EP and CP types of ENSO and briefly discussed as follows. They considered the Niño $1+2$ (Niño 12) index $\left(80-90^{\circ} \mathrm{W} ; 0-10^{\circ} \mathrm{S}\right)$ as an estimate to eliminate the effect of the EP ENSO to that from the CP ENSO. For the CP ENSO, the anomalies in SST are regressed with the Niño 12 SST index first removed from the total anomalies. Then an EOF analysis was applied to obtain a spatial pattern of the CP ENSO. Similarly, for the EP ENSO, they subtracted the SST anomalies regressed with the Niño 4 index from the total anomalies in SST, before applying the EOF technique to identify the leading pattern of the EP ENSO.

The NAO index from the Climate Research Unit (CRU), ${ }^{8}$ University of East Anglia, is used which is available since 1823. It is developed by Jones et al. (1997) that considered instrumental pressure observations from Gibraltar and southwest Iceland. The rest other indices mentioned are all available from free website. ${ }^{5}$ The ISM rainfall data can also be collected from the Indian Institute of Tropical Meteorology (IITM). ${ }^{9}$ It considered three arbitrary regions, Central North East India (covering five subdivisions), all India rainfall (30 subdivisions) and Peninsular rainfall (includes six subdivisions). The details about subdivisions and areas are well documented. ${ }^{\mathbf{5}}$ For IOD, it is collected from KNMI Climate Explorer ${ }^{5}$ and calculated as the difference of SST $\left({ }^{\circ} \mathrm{C}\right)$ from NOAA ERSST (Smith and Reynolds 2004), version 4 (in situ only) from two regions $\left(\left(39^{\circ}\right.\right.$ to $81^{\circ} \mathrm{E}, 15^{\circ} \mathrm{S}$ to $\left.15^{\circ} \mathrm{N}\right)$ and $\left(89^{\circ}\right.$ to $101^{\circ} \mathrm{E}, 11^{\circ} \mathrm{S}$ to $1^{\circ} \mathrm{N}$ )). The SLP (anomaly w.r.t 1951-1980) of Darwin $\left(12.46^{\circ} \mathrm{S}, 130.84^{\circ} \mathrm{E}\right)$ and Tahiti $\left(17.65^{\circ} \mathrm{S}, 149.42^{\circ}\right.$ $\mathrm{W})$ is collected from two websites. ${ }^{10,11}$

To detect significant testing in the trend, Mann-Kendall test (Kendall (1970), Hollander and Wolfe (1994)) is used.

\footnotetext{
$\overline{6} \mathrm{http} / / /$ www.ess.uci.edu/ yu/2OSC/monthly_CP_index_1948_2014.txt

${ }^{7} \mathrm{http}: / /$ www.ess.uci.edu/ yu/2OSC/monthly_EP_index_1948_2014.txt

8 http://www.cru.uea.ac.uk/ timo/projpages/nao_update.htm

${ }^{9}$ http://www.tropmet.res.in/pub/data/rain/iitm-imr-readme.txt

${ }^{10} \mathrm{http}: / /$ www.cgd.ucar.edu/cas/catalog/climind/darwin.anom.ascii

${ }^{11} \mathrm{http} / /$ www.cgd.ucar.edu/cas/catalog/climind/tahiti. anom.ascii
} 


\section{ISM and climate change}

\subsection{Results of regression: Signature on SLP due to volcano}

The radiative effect of a volcano is global cooling irrespective of the period considered, but its actual influence around continents of the Northern Hemisphere (NH) suggests winter warming (Robock and Mao 1992).

Figure 1 shows the result on SLP (DJF) due to volcano over the period 1856 to 2012, as generated using the MLR technique. Positive NAO pattern is clearly distinguished for very strong volcanos. Using reanalysis data of the 20th Century version 2 (20CRv2), a significant surface warming over northern Europe and Asia was detected by Driscoll et al. (2012). Their results from CMIP5 simulation, however, concluded that models fail to capture the Northern Hemispheric dynamical response following eruptions (Driscoll et al. 2012). Here, we focused on explosive volcanos, but in part 1 of this study, Roy and Kripalani 2018 discussed solar variability that also indicates a positive NAO phase during later two decades of the last century. Thus, the combined effects of the sun and strong volcanos, during those decades, have the potential to trigger $\mathrm{CP}$ phase of the ENSO via a preferential alignment of positive NAO phases.

The mechanism relating to positive NAO and CP ENSO was also discussed elaborately in a recent study (Roy 2018c). Apart from modulating CP ENSO, the influence of NAO on changing pattern of ISM was also discussed in various research (Liu and Yanai 2001; Chang et al. 2001).

\subsection{Time series analysis}

The ISM-ENSO relationship is found to have common changing points in the 1970s. Though weakened since 1970s, it showed a recovery in the late 1990s (Yim et al. (2013)). To investigate such connection further, an analysis based on time series of various modes of climate variability is performed with particular emphasis on the period 1976-1996. It covers two full solar cycles, (cycle number 21 and 22) starting from one solar minimum (1976) and ending with another solar minimum (1996). The consecutive solar peak years are 1979 and 1989 with one minimum in between (the year 1986). During that period, two major volcanos erupted during active years of stronger solar cycles. A study suggested separating the period 1979-1997 is important to understand some climate features better (Roy 2016). Such observation was strengthened by very recent studies (Polvani 2017; Oliva 2017) and indicated that it is indeed true.

Figure 2 shows normalised time series of various seasonal modes of climate variability (shown by their subtitles); those might be related to different types of ENSO (EP or CP) and regional ISM rainfall. The top plot (Fig. 2(i)) is during the period 1871-2011 and the bottom (Fig. 2(ii)) for 19572012. For NAO, DJF value is considered and for the rest, seasonal value of JJA is used. Five-year running mean of each series is marked by red in each panel.

The period 1976-1996 is demarcated by black dash lines in Fig. 2(ii). A trend line in that interval is plotted for all series is shown by a blue dashed line.

Noting Fig. 2(i), it can be stated that there is no apparent clear trend in any of those time series for the whole of the
Fig. 1 The signal (max-min, $\mathrm{hPa}$ ) due to the volcano (AOD) in SLP data (DJF) is obtained from a multiple linear regression analysis. Other indices used are SSN and ENSO, and trend and periods used are 1856-2012. Significant regions at the $95 \%$ level using a two-sided Student's $t$ test are shaded and dotted lines indicate negative contours

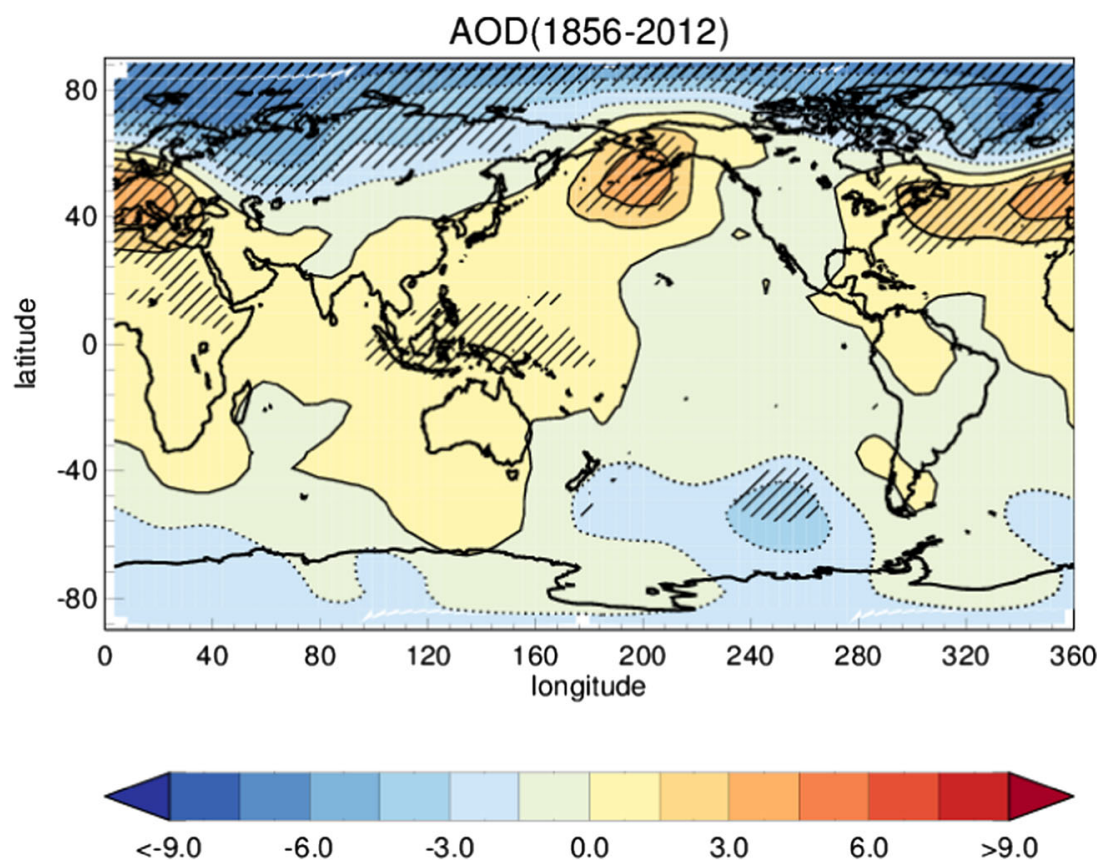


a) Nino3.4

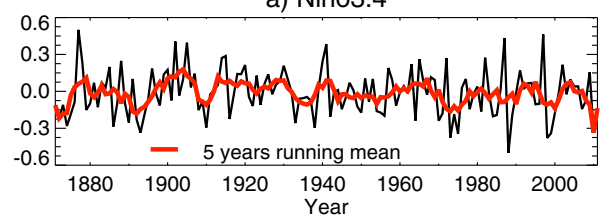

c) SLP(Darwin)

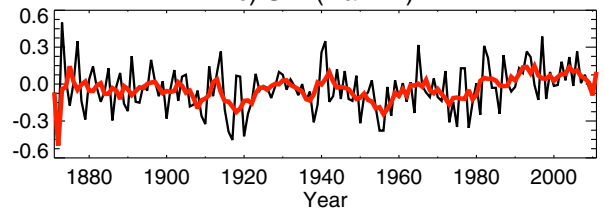

e) IOD

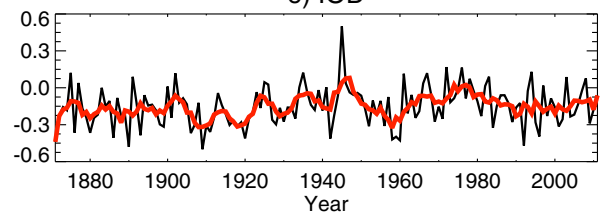

g) ISM Precipitation(All India)

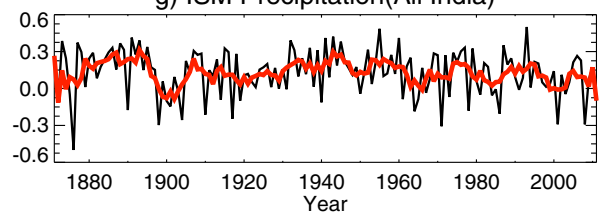

b) Nino12

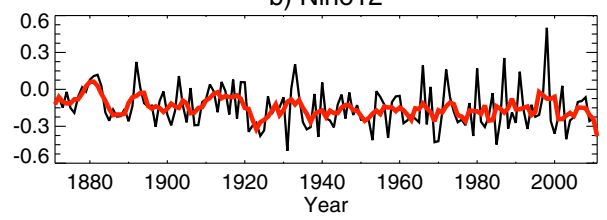

d) SLP(Tahiti)

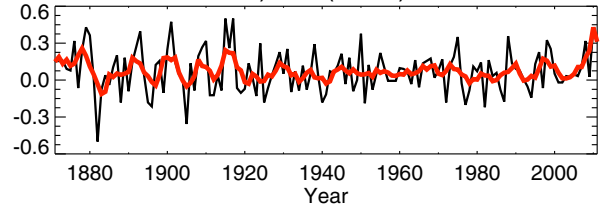

f) ISM Precipitation(CNE)

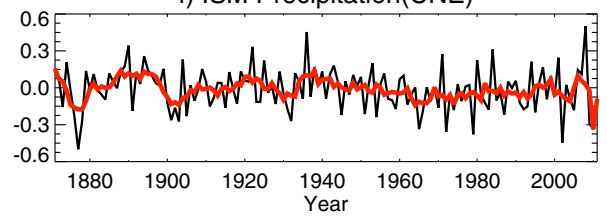

h) ISM Precipitation(South Penninsular)

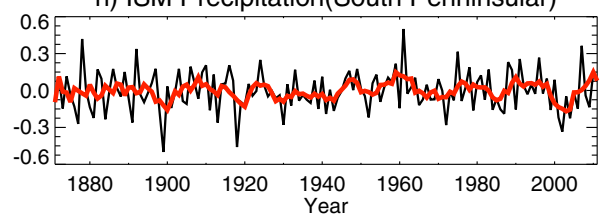

EP-ENSO
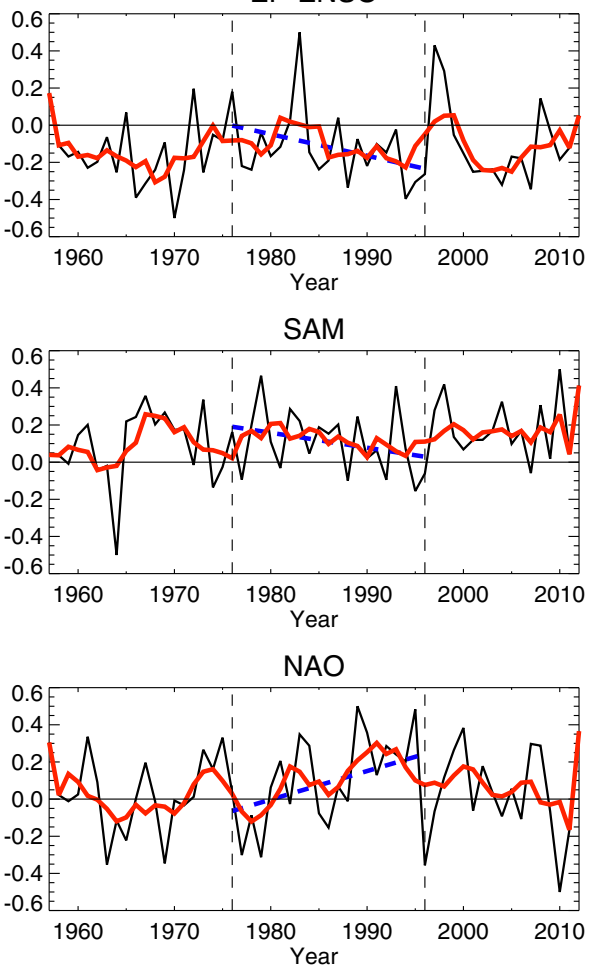

in each panel. A trend line is plotted during 1976-1996 for all series of bottom panel and shown by a blue-dashed line. Black-dashed lines demarcate the time period of 1976-1996
Fig. 2 Normalised time series of various seasonal modes of climate 1957-2012 (bottom panel). For all cases, JJA value is considered, while for NAO, it is DJF. A 5-year running mean of each series is marked by red 
record. We could not identify a decreasing trend of ISM (IPCC 2013) in the arbitrarily chosen regional rainfall pattern. It could be due to a precise location of CNE India, covering the ITCZ that only showed the decreasing trend in a spatial pattern (Bollasina et al. (2011) and Goswami et al. (2006)). The time series of regional ISM considered here might have other opposing local influences. Interestingly, when the focus is around 1976-1996, a clear trend is noticed for SLP Darwin and IOD (Fig. 2(i)). Hence, we analyse it further in Fig. 2(ii) considering a shorter record (1957-2012) demarcating that 20-year period.

Time series of few other parameters were presented which are thought might be linked to those two parameters (IOD and SLP Darwin). SLP around Darwin was chosen because an increase in SLP here strengthens ITCZ. The rise in pressure gradient between Darwin and ITCZ enhances the flow of moist rich ocean air. More air from the Indian Ocean converge towards the land region of India and increase rainfall. $\mathrm{CP}$ and EP ENSO series are constructed since 1948 ((Kao and Yu 2009; Yu and Kim 2010) and we presented those in Fig. 2(ii) as those are more relevant to our discussion. Among various parameters in Fig. 2(ii), there is a clear rising trend for CP ENSO, NAO and SLP Darwin during 1976-1996, while a decreasing trend for EP ENSO and IOD. All the parameters suggest nominal, an insignificant rising trend over the whole period (1957-2012).

CP ENSO indicated a clear upward trend (11\% per decade, increased significantly; for a whole period it is $1.4 \%$ ) which is consistent with the observation that ENSO Modoki became more familiar since the 1970s up to late 1990s. It is in agreement with the rising trend of NAO $(+15 \%$ per decade, whole $1.3 \%$ ). The connection between CP ENSO and NAO, both suggest an increasing trend, agrees with the proposed mechanism of Bjerknes (Bjerknes 1966)) and also the mechanism involving extratropical Rossby waves (Ham et al. 2013a, b). Bjerknes 1966 discussed that the major warming along the equatorial and central Pacific during northern winter is often accompanied by an anomalous strength of the mid-latitude westerlies and vice versa. Annular modes in NH have exhibited pronounced trends towards high-index polarity also documented by Hurrell (1996) and Thompson et al. (2000). The EP ENSO, on the other hand, shows a decreasing trend ($11 \%$ per decade, but not significant; whole $0.4 \%$ ).

The influence of ENSO Modoki on Southern Hemisphere storm track activity during JJASO (June-July-AugustSeptember-October) was discussed by Ashok et al. 2009. It showed El Niño Modoki introduces a blocking over central eastern Australia which subsequently suppresses the regional storm track activity. Following an increase of ENSO Modoki since the 1970s, it would undoubtedly suggest a rise in SLP around Darwin, Australia, as also noticed in Fig. 2(ii) (trend = $+15 \%$ per decade, whole 3.8\%). Roy and Collins (2015) also noticed that the SLP of Darwin is strongly influenced during later periods. Thus, ENSO Modoki through blocking over Australia, one end of IOD, can have potential to influence IOD and subsequently ISM (trend of IOD $=-20 \%$ per decade, significant at $95 \%$ level; whole .3\%). Following the definition of IOD as used here, the direction of the trend for IOD and SLP of Darwin suggests a consistent result. There could be an argument that if SLP of Darwin has the potential to influence ISM, then a clear trend observed there should also be seen in ISM rainfall time series. But it is not the case because ISM is not only regulated by moisture convergence from the Indian Ocean alone. Large-scale circulation features like Walker circulation and regional Hadley circulation also plays dominant roles, apart from other local influences. All those forcing acts in a complex nonlinear manner to produce the actual response on ISM and hence no clear trend is noticed.

The response relating to Hadley cell and upper air midlatitude westerlies can be explained by the mechanism proposed by Bjerknes (Bjerknes (1966)) and is expected to be strongest in the winter hemisphere due to greater baroclinicity. Hence, it would also be captured in the strength of SAM. The ENSO Modoki which is dominant since the 1970s, though suppresses rainfall over India, enhances rainfall over North and South America. Rainfall in central Argentina is also increased owing to the strengthened upper air westerlies (Ashok et al. (2009)). Amita et al. (2016) studied trends in SAM during1949-2013 and found that the data from post-1982 does not show significant long-term trends. It is because of opposing nature of the strength of westerlies around the whole of the mid-latitude to that from Darwin of Australia. That could be one responsible factor to suggest null results for SAM trend when considered in a zonal sense. It is consistent with the current analysis as we also could not identify a significant rising trend for SAM (trend is only $-8 \%$ per decade and insignificant) during that period (the whole trend is $+2 \%$ ). In the subsequent section, there will be more focus on the NAO, IOD and SLP at Darwin of Australia.

\subsection{Observation and CMIP5 model results: SLP anomaly}

\subsubsection{Spatial patterns of SLP (JJA)}

From the last 100 years of Darwin's mean sea level pressure record of last century, Trenberth and Hoar (1996) reported that the Darwin pressure has tended to be above its long-term normal since 1977 and suggested it might be due to the influence of the enhanced greenhouse effect on the climate system. However, contrary to that, Harrison and Larkin (1997) indicated about the impact of natural variability on the tropical Pacific.

Mean surface pressure (which is similar to SLP) is plotted in Fig. 3 during June-August (JJA) with a special focus on the Indian Ocean region. The spatial pattern 
Fig. 3 Mean surface pressure (hPa, June-Aug.): 1976-1996 minus 1956-1975 (right); 19761996 minus 1997-2016 (left).

The top panel shows observational data from HadSLP2r, while the bottom panel uses ensemble mean of GCM, CMIP5 (IPCC AR5) subset model. The signal smaller than one standard deviation of natural variability is shown by hatching. Plots generated using the IPCC's Climate Change Atlas, climexp.knmi.nl/plot atlas_form.py
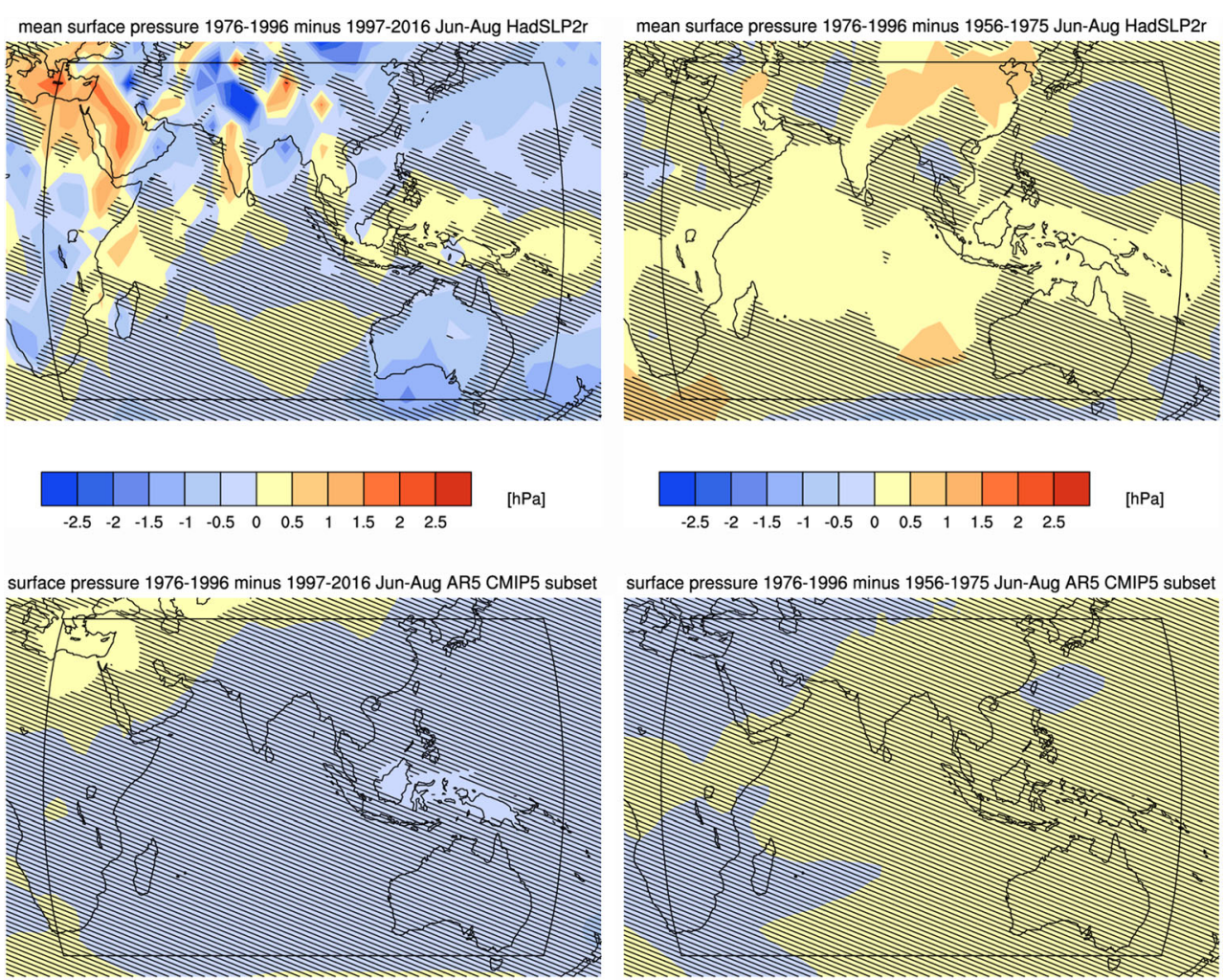

[hPa]

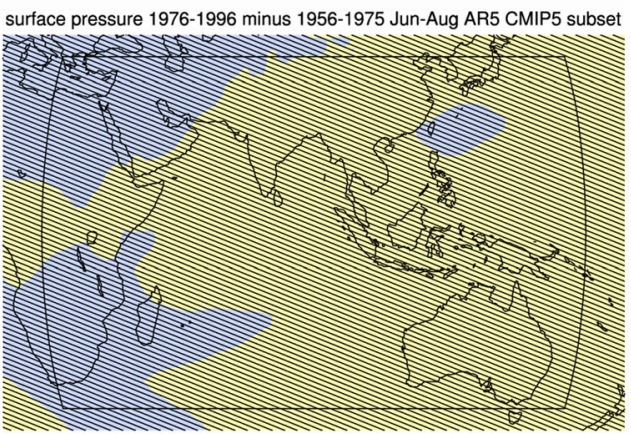

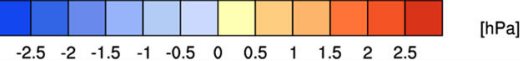

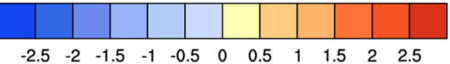

[hPa]

using ensemble mean of AR5 CMIP5 subset model (bottom) indicates a reduction of pressure during 19761996 w.r.t. reference period 1997-2016 (left) around Darwin of Australia, and regions of IOD. Consistent with longer term trend, similar locations suggest an increase in pressure when the reference period is switched to 19561975 (right). Interestingly, respective figures using observational data of HadSLP2r (top) deviate to that from model results. Places around Darwin of Australia show a rise in pressure for both the cases of observation. Moreover, parts of the Indian subcontinent, and regions of east Africa, where the influence of IOD is felt, also show an enhancement in both cases. Such analyses indicate the influence of surface pressure around Darwin of Australia, and regions of IOD show some special characteristics (a rise) during 1976-1996, which is different to that from the signal of a longer trend. Model results fail to detect it but capture well the longer term trend instead. In left, surface pressure around Darwin of Australia is shown by blue in the model, which is brown in observation. Those signatures are not only reverse in nature, but in both cases, even higher than one standard deviation of natural variability (shown without hatching).

Two arbitrarily chosen CMIP5 models (CanESM2 and IPSL-CM5A-LR) are also tested for mean surface pressure
(JJA) in Fig. 4. There is no consistency noticed in these two models. In the Indian Ocean region, CanESM2 is dominated by blue in both the anomaly period (earlier or recent), whereas IPSL-CM5A-LR suggests red.

\subsubsection{Temporal pattern of SLP (JJA)}

Time series plots of various CMIP5 model SLP anomalies (w.r.t. 1951-1980) around Darwin of Australia during JJA are presented in Fig.5. It highlights the diverse behaviour of SLP (Darwin) among models, where the model peaks and troughs are seen very unlike to match with each other, let alone with the observation (Fig. 2). Observed SLP (Darwin) in Fig. 2 suggests a clear rising trend during period within dotted lines, but models suggest inconsistency. Some models show a clear rising trend (bcc-csm1-1, GISS-E2-R), some a declining trend (ACCESS1-0, ACCESS1-3, bcccsm1-1-m), whereas most models indicate a nominal trend. In terms of variability, models also differ among each other and with the observation. During the intervening period (1976-1996), some models suggest larger variability (BNUESM, GISS-E2-R), while some indicate smaller variability (CESM1-BGC). Models also do not follow observed SLP behaviour, in the recent period, the period after the red dotted lines. 


\subsubsection{Spatial patterns of SLP (DJF)}

Figure 6 is the same as Fig. 3 respectively but depicts the North Atlantic region for DJF season. The places around Icelandic Low and Azores High in models (bottom) clearly detect longer term trend (opposite signature in two plots) for surface pressure. However, models cannot distinguish any patterns of NAO and signals are similar in those two places on the right as well as the left plot. The observational data from HadSLP2r suggests differently to that from models in terms of NAO pattern. Positive NAO feature is distinct in the right panel, which even exceeds the range of natural variability around the Icelandic Low and Azores High. Unlike model results, the opposite signal is also noticed in those two places, in the left panel, though deviation lies within the range of natural variability. Moreover, negative NAO pattern is not very distinct in that left plot. Interestingly, observation suggests the opposite to that from model in both cases around the
Icelandic Low. Time series analyses for SLP (DJF) were also examined around two different places, Icelandic Low and Azores High, from the north Atlantic. It is the same as Fig. 5 and again suggested similar diverse behaviour of SLP (DJF) among models, as expected (hence not shown here).

All these studies suggest local N-S Hadley circulation, as manifest as NAO in the $\mathrm{NH}$ and IOD in the SH may have played a role in modulating ISM in later decades of last century (1976-1996). Such features are captured in observation but missed by models. Observation suggests a complex interplay among NAO and IOD on ISM via Hadley circulation. It has potentials to modulate ISM, which is not captured by models. Roy and Tedeschi (2016) showed almost all CMIP5 models poorly represent the observed influence of meridional circulation on ISM. Those meridional components of wind in models deviate largely from observation, but surprisingly consistent among each other. Apart from the influence of E-W Walker circulation on ISM, the contributions from N-S
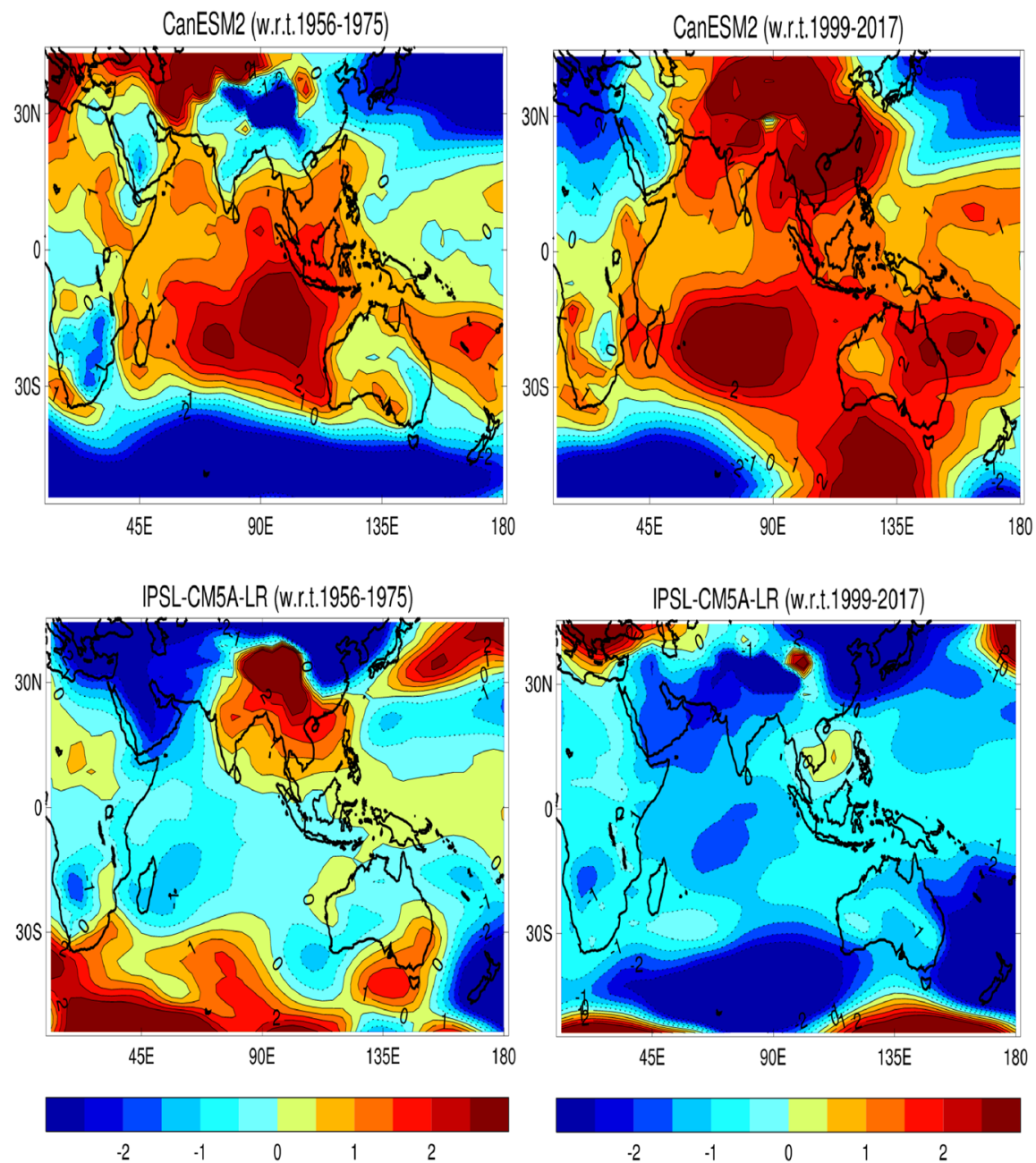

Fig. 4 Mean surface pressure (hPa, June-Aug.): 1976-1996 minus 1956-1975 (left); 1976-1996 minus 1999-2017 (right) for two arbitrarily chosen CMIP5 models, CanESM2 (top) and IPSL-CM5A-LR (bottom) 

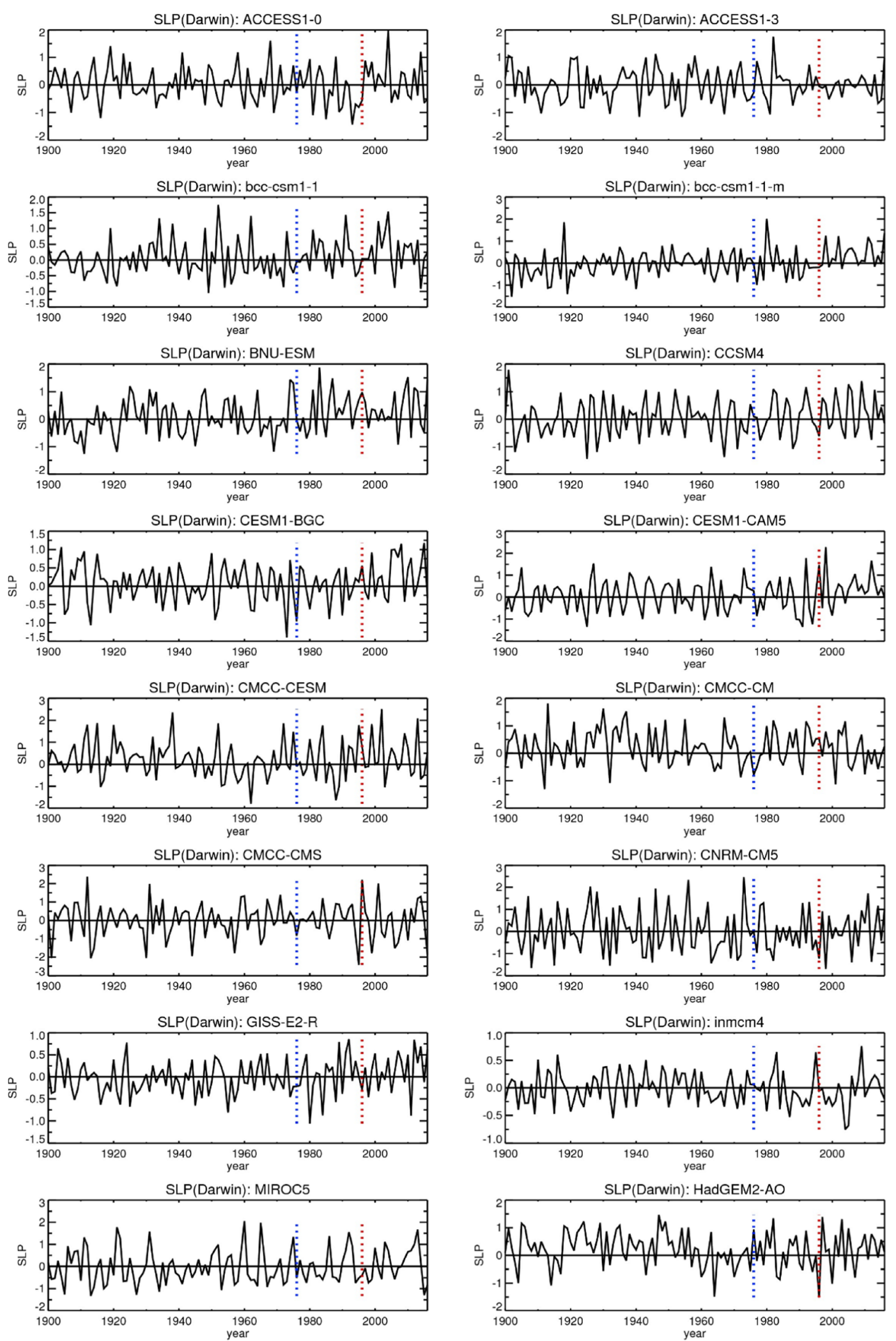

Fig. 5 SLP (hPa) anomaly (June-August) time series around Darwin for various CMIP5 models since 1900. After 2005, the future period is extended by RCP85 scenario. The period 1976-1996 is marked by

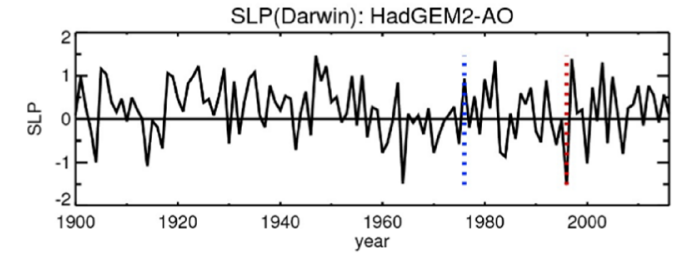

coloured dotted lines and the period exceeding red dotted lines represent the recent period of change in ISM teleconnection pattern 
Hadley cell need additional attention, which were shown to be more relevant during the later two decades of the last century.

\subsection{Discussion on limitations of models}

Various research (Roy 2017; Turner and Annamalai 2012; Annamalai et al. 2007) explored model simulations of ISM and ENSO and discussed limitations where models disagree with observation. Here, we studied global hydrological cycle to address further on what areas models agree in general (Fig. $7 \mathrm{a}-\mathrm{d}$ ) and where lies major discrepancies. It relies on a very wellknown established relationship of the thermodynamic equation on global hydrological cycle (Vecchi and Soden 2007; Held and Soden 2006) that follows Clausius-Clapron (C-C) equation.

The change in global-mean quantities for various CMIP5 models using equation of global hydrological cycle are plotted (following Vecchi and Soden 2007, equ 1) annually (Fig. 7a and b); and June-Sept. (JJAS) (Fig. 7c, d). It is a similar plot like Vecchi and Soden (2007) (their Fig. 2), but we used the CMIP5 model instead of CMIP3. In Fig. 7, results are shown for (a) surface temperature (T) vs. column-integrated atmospheric water vapour (Hus) (\%); (b-d) precipitation (Pr) vs. a combination of vertical velocity (Wap) and surface temperature $(\mathrm{T})(\%)$. The differences are computed by subtracting the means from the last 20 years of historical period and last 20 years of the twenty-first century as projected by the RCP85 scenario ((20812100)-(1986-2005)) w.r.t. latest decades from the historical period (1986-2005). Instead of (1986-2005), if we use (1976-1996), the result remains very similar. Vecchi and Soden (2007) used different periods but results are practically unaltered using their periods too.

There are also other differences in our analyses. They however only considered global analyses annually, but we used the JJAS period and considered the Indian region too. Moreover, we plotted slightly different parameters (\%) (though meaning of those figures imply similar) from the Clausius-Clapron (CC) equation, which can be represented as

$$
\frac{{ }^{\prime} \Delta M}{M}=\frac{\Delta \operatorname{Pr}}{\operatorname{Pr}}-0.07 \Delta T
$$

(after Vecchi and Soden 2007, their Eq. 1).

Where, $M$ is the convective mass flux, $\mathrm{Pr}$ is the precipitation and $\mathrm{T}$ the temperature (those terms and their relevance are discussed in detail in Vecchi and Soden (2007).

The bottom right plot (d) shows only the Indian region, while rest three cover the whole globe. There are good agreements among models for global analyses (Fig. 7a-c)
Fig. 6 Same as Fig. 3, but mean surface pressure is for Dec.-Feb. with a particular focus on the North Atlantic region
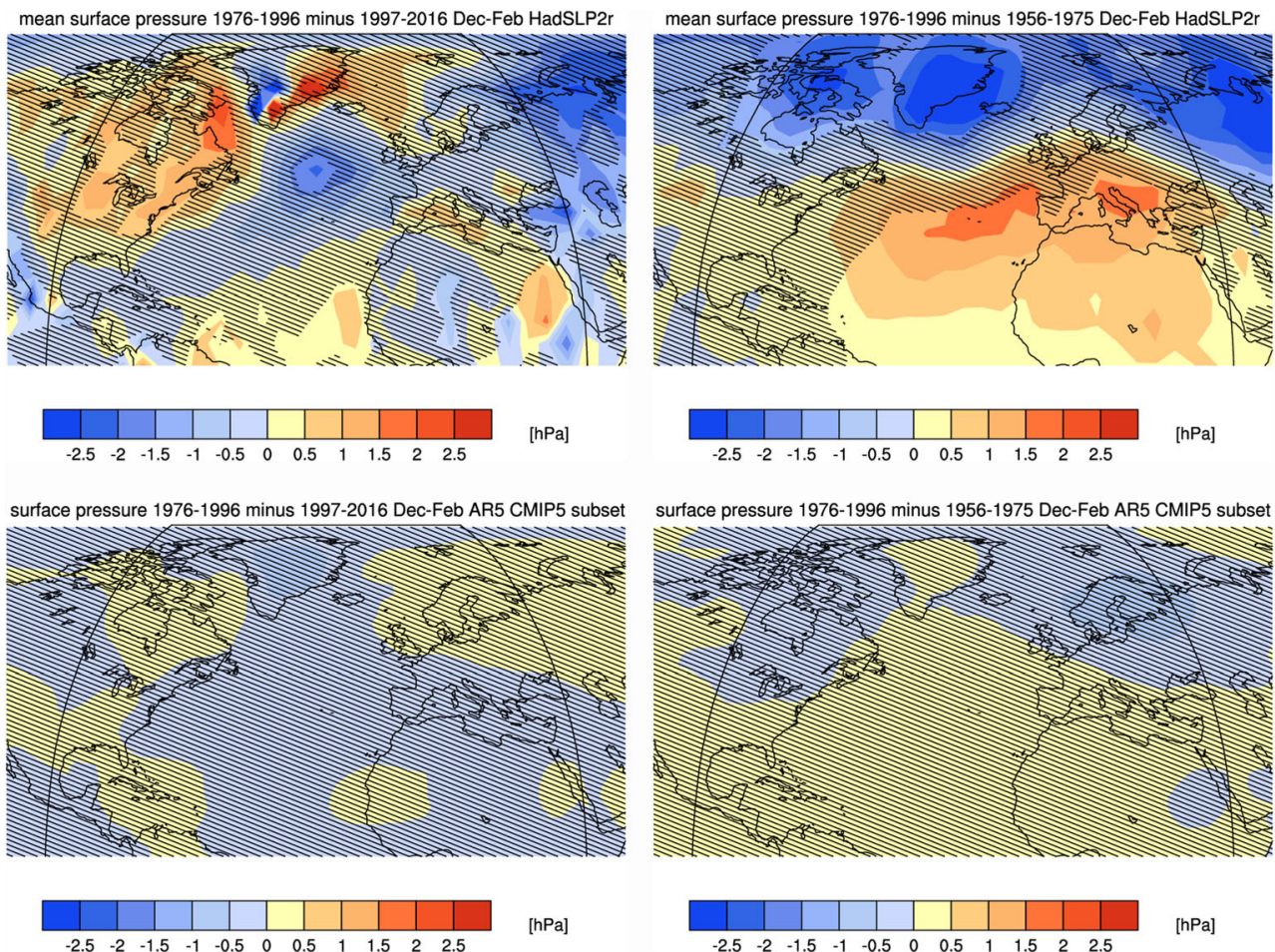

$[\mathrm{hPa}]$

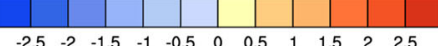

[hPa] 
Fig. 7 Scatterplots of the change in global-mean quantities for various CMIP5 models using the equation of global hydrological cycle, annually (a, b) and JuneSept. (JJAS) (c, d). Results are shown for (a) surface temperature $(T)$ vs. column-integrated atmospheric water vapour (Hus) (\%); (b-d) precipitation (Pr) vs. a combination of vertical velocity (Wap) and surface temperature (T) (\%). The bottom right plot (d) shows the Indian region, while rest three cover the whole globe. There is good agreement among models for global analyses $(\mathbf{a}-\mathbf{c})$ as also shown by the correlation coefficient (c.c)

Annual

a Atmospheric water vapour and temp

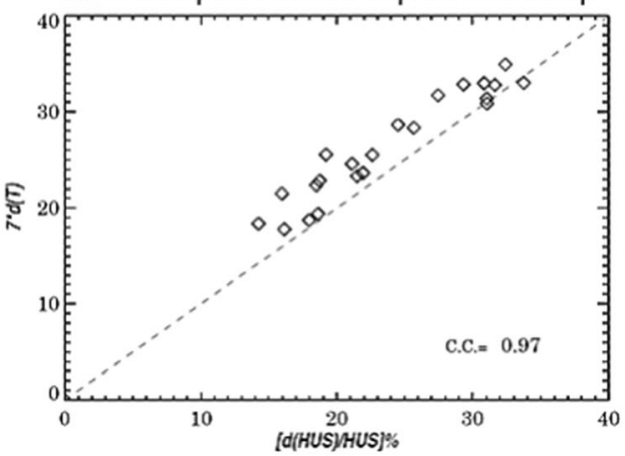

JJAS

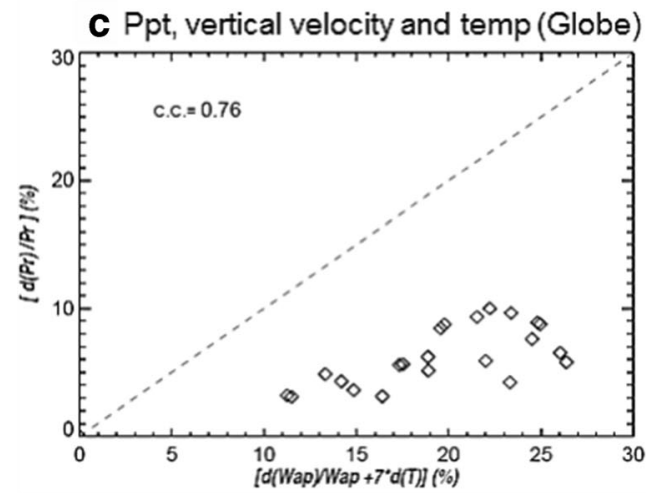

b Precipitation, vertical vel and temp
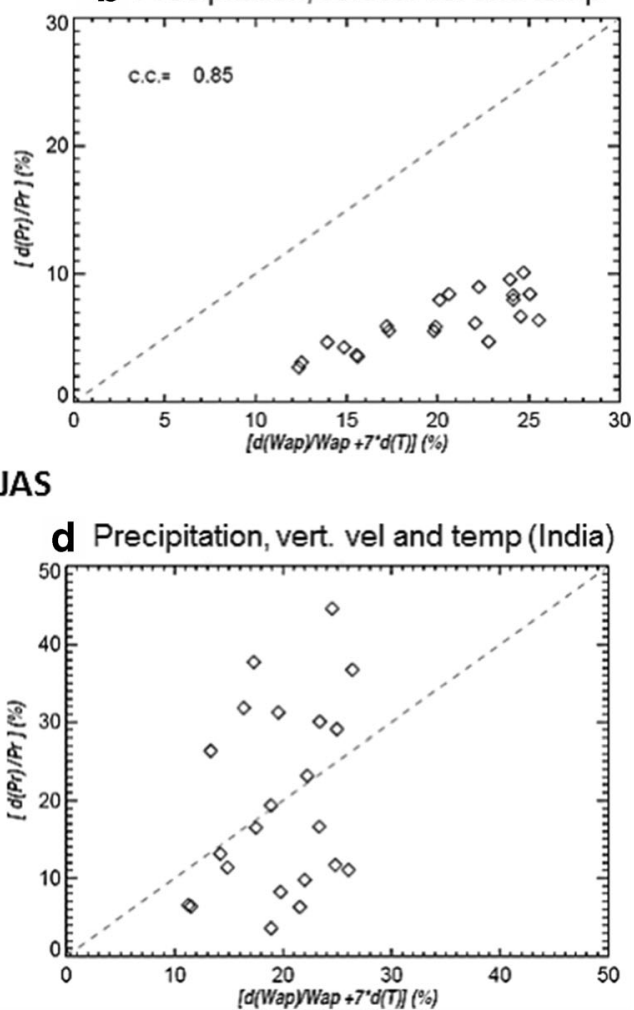

as also shown by correlation coefficient (c.c.). It indicates though moistening varies model to model, all models exhibit a nearly linear relationship between column water vapour and surface temperature, when considered globally. The rate of this increase is $\sim 7 \% / \mathrm{K}$, following the Clausius-Clapron (C-C) equation (represent a diagonal line of Fig. 7a, like Vecchi and Soden (2007), their Fig. 2a). Even doing the global analyses annually (Fig. 7a, b) or seasonally (JJAS), the main observation of good correlation among models does not change. The shift among models in Fig. $7 \mathrm{~b}$ and $\mathrm{c}$ represents reduction due to circulation (Vecchi and Soden 2007). Interestingly, when only the Indian region is focused, models indicate inconsistency (Fig.7d). It indicates, although there can be significant regional changes in relative humidity among models, the global-mean behaviour closely resembles that expected from (C-C) arguments also in CMIP5.

Not only models suggest inconsistency in the Indian region, but it also contradicts the proposed hypothesis based on thermodynamic scaling arguments (Vecchi and Soden 2007; Held and Soden 2006). A decreasing trend in precipitation around India is detected in observations (Ramanathan et al. 2005, Chung and Ramanathan 2006, Goswami et al. (2006)), which disagree thermodynamic scaling argument. Improved representation of forcing due to natural factors on circulation-related field (Walker as well as regional Hadley circulation) could be a major step forward for advance understanding of ISM under climate change scenario.

\section{Discussion}

Various teleconnections on ISM are presented analysing CMIP5 models and observations. Focusing on later two decades of the last century, how such connections could have been disturbed is explored. In spite of the linear rising anthropogenic influence of recent few decades, the specific later two decades of the twentieth century clearly suggested some distinguishing features which were captured by observation. During that period, the role of explosive volcanos and that of the sun, both triggered positive phase of the NAO, which could be one important factor for possible disruption. We discussed that positive NAO has the potential to influence north Pacific and subsequently can modulate the CP ENSO phase. Over the same period, a significant rising trend for CP ENSO, NAO and SLP around Darwin of Australia is identified. The overall study also addresses how local N-S Hadley circulation, as manifests as NAO 
in the NH and IOD in the SH, could have played roles in modulating ISM in later decades of the twentieth century. Interestingly, such observed features are missed by models. Not only individual model and model ensemble show inconsistencies, but all models also vary widely among each other.

We further studied global hydrological cycle to address areas where models agree in general. It indicated that CMIP5 models suggest consistency among each other in global scale in terms of thermodynamic scaling argument. Differences among models mainly originate on a regional level, which is likely due to missing out regional teleconnection features. The overall study underpins important areas, where natural factors influence regional climate, by affecting circulation fields, but models miss out and suggest discrepancies. Such knowledge has implications in a regional as well as global scales and the modelling community will greatly benefit from such analyses. It will help improve model skills by better representations of ISM teleconnection via regional Hadley and Walker cell.

Acknowledgments Authors acknowledge various centres for providing freely available data ${ }^{1-11}$; those include the Met Office Hadley Centre, UK and NOAA, USA. Many of the data used are also collected from KNMI Climate Explorer site 5

Abbreviations AOD, Aerosol Optical Depth; C-C, Clausius-Clapron; CMIP5, Coupled Model Intercomparison Project 5; CNE, Central North East; CP, central Pacific; CRU, Climate Research Unit; DJF, December January February; ENSO, El Niño Southern Oscillation; EOF, Empirical Orthogonal Function; EP, Eastern Pacific; ERSST, Extended Reconstructed Sea Surface Temperature; IITM, Indian Institute of Tropical Meteorology; IOD, Indian Ocean Dipole; ISM, Indian Summer Monsoon; ITCZ, Intertropical Convergence Zone; JJA, June July August; JJASO, June July August September October; NAO, North Atlantic Oscillation; NH, Northern Hemisphere; Niño 12, Niño region 1+2; RCP, Representative Concentration Pathway; SAM, Southern Annular Mode; SH, Southern Hemisphere; SSN, Sunspot Number; SST, Sea Surface Temperature; SLP, Sea Level Pressure

Open Access This article is distributed under the terms of the Creative Commons Attribution 4.0 International License (http:// creativecommons.org/licenses/by/4.0/), which permits unrestricted use, distribution, and reproduction in any medium, provided you give appropriate credit to the original author(s) and the source, provide a link to the Creative Commons license, and indicate if changes were made.

\section{References}

Adams JB, Mann ME, Ammann CM e a (2003) Proxy evidence for an El Niño-like response to volcanic forcing. Nature 426:274-278. https:// doi.org/10.1038/nature02101

Amita P, Kripalani RH, Preethi B, Pandithurai (2016) Potential role of the February-March Southern Annular Mode on the Indian summer monsoon rainfall: a new perspective. Climate Dynamics 47(3-4):1161-1179. https://doi.org/10.1007/s00382015-2894-5
Annamalai H, Hamilton K, Sperber KR (2007) The south Asian summer monsoon and its relationship with ENSO in the IPCC AR4 simulations. J Clim 20(6):1071-1092

Annamalai H, Hafner J, Sooraj KP, Pillai P (2013) Global warming shifts the monsoon circulation, drying South Asia. J Clim 26:2701-2718

Ashok K, Yamagata T (2009) Climate change: the El Niño with a difference. Nature 461:481-484. https://doi.org/10.1038/ $461481 \mathrm{a}$

Ashok K, Guan Z, Yamagata T (2001) Impact of Indian Ocean dipole on the relationship between the Indian monsoon rainfall and ENSO. Geo Res Lett 28(23):4499-4502

Ashok K, Behera SK, Rao SA, Weng H, Yamagata T (2007) El Niño Modoki and its possible teleconnections. J Geophys Res 112: C11007. https://doi.org/10.1029/2006JC003798

Ashok K, Tam CY, Lee WJ (2009) ENSO Modoki impact on the southern hemisphere storm track activity during extended austral winter. Geophys Res Lett 36:L12705. https://doi.org/10.1029/ 2009GL038847

Bjerknes J (1966) A possible response of the atmospheric Hadley circulation to equatorial anomalies of ocean temperature. Tellus 18(4): 820-829. https://doi.org/10.1111/j.2153-3490.1966.tb00303

Bollasina MA, Ming Y, Ramaswamy V (2011) Anthropogenic aerosols and the weakening of the south Asian summer monsoon. Science 334(6055):502-505. https://doi.org/10.1126/science.1204994

Brönnimann S, Ewen T, Griesser T, Jenne R (2006) Multidecadal signal of solar variability in the upper troposphere during the 20th century. Space Sci Rev 125(1-4):305-317. https://doi.org/10.1007/s11214006-9065-2

Cai W, Cowan T (2009) La Niña Modoki impacts Australia autumn rainfall variability. Geophysical Research Letter 36:L12805

Cash BA, Barimalala R, Kinter JL, Altshuler EL, Fennessy MJ, Manganello JV, Molteni F, Towers P, Vitart F (2017) Sampling variability and the changing ENSO-monsoon relationship. Clim Dyn 48(11):4071-4079

Chang CP, Harr P, Ju J (2001) Possible roles of Atlantic circulations on the weakening Indian monsoon rainfall-ENSO relationship. J Clim 14:2376-2380

Chung CE, Ramanathan V (2006) Weakening of the north Indian SST gradients and the monsoon rainfall in India and the Sahel. J Clim 19: 2036-2045

Driscoll S, Bozzo A, Gray LJ, Robock A, Stenchikov G (2012) Coupled model inter-comparison project 5 (CMIP5) simulations of climate following volcanic eruptions. J Geophys Res 117(D17). https://doi. org/10.1029/2012JD017607

Emile-Geay J, Seager R, Cane MA, Cook ER, Haug GH (2008) Volcanoes and ENSO over the past millennium. J Clim 21:3134 3148

Gill AE (1980) Some simple solutions of heat induced tropical circulations. Q J R Meteorol Soc 106:447-462

Goswami BN, Venugopal V, Sengupta D, Madhusoodanan MS, Xavier PK (2006) Increasing trend of extreme rain events over India in a warming environment. Science 314:1442-1445

Haigh JD, Blackburn M, Day R (2005) The response of tropospheric circulation to perturbations in lower-stratospheric temperature. $\mathrm{J}$ Clim 18(17):3672-3685

Ham Y-Y, Kug J-S, Park JY, Jin F-F (2013a) Sea surface temperature in the north tropical Atlantic as a trigger for El Nina/Southern Oscillation events. Nat Geosci 6:112-116. https://doi.org/10.1038/ NGEO1686

Ham Y-Y, Kug J-S, Park JY, Jin F-F (2013b) Two distinct roles of Atlantic SSTs in ENSO variability: north tropical Atlantic SST and Atlantic Niño. Geophys Res Lett 40:4012-4017

Harrison DE, Larkin NK (1997) Darwin Sea level pressure, 1876-1996: evidence for climate change? Geophys Res Lett 24:1779-1782. https://doi.org/10.1029/97GL01789. issn: 0094-8276 
Held and Soden (2006) Robust responses of the hydrological cycle to global warming. J Clim 19:5686-5699

Hill KJ, Taschetto AS, England MH (2009) South American rainfall impacts associated with inter-El Niño variations. Geophys Res Lett 36:L19702. https://doi.org/10.1029/2009GL040164

Hollander M, Wolfe DA (1994) Nonparametric Statistical Methods, 2nd Edition. Wiley-Interscience. ISBN-10: 0471190454, ISBN-13: 9780471190455

Huang P, Xie SP, Hu K, Huang G, Huang R (2013) Patterns of the seasonal response of tropical rainfall to global warming. Nat Geosci 6:357-361

Hurrell et al (1996) Influence of variations in extratropical wintertime teleconnections on northern hemisphere temperature. Geophysical Research Letter 23:665-668. https://doi.org/10.1029/96GL00459

IPCC (2013) Climate Change, The Physical Science Basis. Contribution of Working Group I to the Fifth Assessment Report of the Intergovernmental Panel on Climate Change. Cambridge: Cambridge University Press, 1535 pp. doi: https://doi.org/10.1017/ CBO9781107415324

Jones PD, Jonsson T, Wheeler D (1997) Extension of the North Atlantic Oscillation using early instrumental pressure observations from Gibraltar and southwest Iceland. Int J Climatol $17: 1433-1450$

Kao H-Y, Yu J-Y (2009) Contrasting eastern-Pacific and central-Pacific types of El Nino. J Clim 22:615-632

Kaplan A, Cane M, Kushnir Y, Clement A, Blumenthal M, Rajagopalan B (1998) Analyses of global sea surface temperature 1856-1991. J Geophys Res 103(18):567-18,589

Kendall MG (1970) Rank correlation methods, 4th edn. Griffin, London

Kripalani RH, Kulkarni A (1997) Climate impact of El Nino/La Nina on the Indian monsoon: a new perspective. Weather 52: $39-46$

Kug J-S, Jin F-F, An S-I (2009) Two types of El Niño events: cold tongue El Niño and warm pool El Niño. J Clim 22:1499-1515

Kumar KK, Rajagopalan B, Cane MA (1999) On the weakening relationship between the Indian monsoon and ENSO. Science 284(5423): 2156-2159

Larkin NK, Harrison DE (2005) On the definition of El Niño and associated seasonal average U.S. weather anomalies. Geophys Res Lett 32:L13705. https://doi.org/10.1029/2005GL022738

Lee JN, Shindell DT, Hameed S (2009) The influence of solar forcing on tropical circulation. J Clim 22:5870-5885. https://doi.org/10.1175/ 2009JCLI2670.1

Liu X, Yanai M (2001) Relationship between the Indian monsoon rainfall and the tropospheric temperature over the Eurasian continent. Quart J Roy Meteor Soc 127:909-937

Lorenzo E.D., K. M. Cobb, J. C. Furtado et al. (2010): Central Pacific El Niño and decadal climate change in the North Pacific Ocean, Nat Geosci 1-4. DOI: https://doi.org/10.1038/NGEO984

Maity R, Kumar DN (2006) Bayesian dynamic modelling for monthly Indian summer monsoon rainfall using El Niño-Southern Oscillation (ENSO) and Equatorial Indian Ocean Oscillation (EQUINOO). J Geophys Res 111:D07104

McPhaden MJ, Lee T, McClurg D (2011) El Nino and its relationship to changing background conditions in the tropical Pacific Ocean. Geophys Res Lett 38:L15709. https://doi.org/10.1029/ 2011GL048275

Meehl GA, Arblaster JM, Matthes K, Sassi F, van Loon H (2009) Amplifying the Pacific climate system response to a small 11-year solar cycle forcing. Science 325:1114-1118. https://doi.org/10. 1126/science. 117287

Miller J, Cayan DR, Barnett TP, Graham NE, Oberhuber JM (1994) The 1976-77 climate shift of the Pacific Ocean. Oceanography 7:21-26. https://doi.org/10.5670/oceanog.1994.11

Ohba M, Shiogama H, Yokohata T, Watanabe M (2013) Impact of strong tropical volcanic eruptions on ENSO simulated in a coupled GCM.
American Meteorological Society 26:5169-5182. https://doi.org/10. 1175/JCLI-D-12-00471.1

Oliva et al (2017) Recent regional climate cooling on the Antarctic peninsula and associated impacts on the cryosphere. Sci Total Environ 580:210-223

Polvani et al (2017) The impact of ozone-depleting substances on tropical upwelling, as revealed by the absence of lower-stratospheric cooling since the late 1990s. J Clim 30:2523-2534. https://doi.org/10.1175/ JCLI-D-16-0532.1

Ramanathan V, Chung C, Kim D, Bettge T, Buja L, Kiehl JT, Washington WM, Fu Q, Sikka DR, Wild M (2005) Atmospheric brown clouds: impacts on south Asian climate and hydrological cycle. Proc Natl Acad Sci U S A 102(15):5326-5333

Robock A, Mao J (1992) Winter warming from large volcanic eruptions. Geophys Res Lett 19(24):2405-2408. https://doi.org/10.1029/ 92GL02627

Roxy et al (2015) Drying of Indian subcontinent by rapid Indian Ocean warming and a weakening land-sea thermal gradient. Nature Communications 6:7423. https://doi.org/10.1038/ncomms8423

Roy I (2014) The role of the sun in atmosphere-ocean coupling. Int J Climatol 34(3):655-677. https://doi.org/10.1002/joc.3713

Roy I (2016) The role of natural factors on major climate variability in Northern Winter. Preprints 2016080025. doi: https://doi.org/10. 20944/preprints201608.0025.v1

Roy I (2017) Indian summer monsoon and El Niño southern oscillation in CMIP5 models: a few areas of agreement and disagreement. Atmosphere 8(8):154. https://doi.org/10.3390/atmos8080154

Roy I (2018a) 'Climate variability and sunspot activity - analysis of the solar influence on climate', publisher Springer Nature. Sole authored book, 18 chapters, 216 pages. ISBN 978-3-319-77107-6. DOI: https://doi.org/10.1007/978-3-319-77107-6

Roy I (2018b) Solar cyclic variability can modulate winter Arctic climate. Sci Rep, Nature publication 8:4864. https://doi.org/10.1038/s41598018-22854-0

Roy I (2018c) Addressing on abrupt global warming, warming trend slowdown and related features in recent decades. Frontiers 6:136

Roy, Collins (2015) On identifying the role of Sun and the El Niño Southern Oscillation on Indian summer monsoon rainfall. Atmos Sci Let 16:162-169. https://doi.org/10.1002/as12.547

Roy I, Haigh JD (2010) Solar cycle signals in sea level pressure and sea surface temperature. Atmos Chem Phys 10(6):3147-3153

Roy I, Haigh JD (2011) The influence of solar variability and the quasi-biennial oscillation on lower atmospheric temperatures and sea level pressure. Atmos Chem Phys 11:11679-11687, ISSN:1680-7316. https://doi.org/10.5194/acp-11-11679-2011

Roy I, Haigh JD (2012) Solar cycle signals in the Pacific and the issue of timings. J Atmos Sci 69(4):1446-1451. https://doi.org/10.1175/ JAS-D-11-0277.1

Roy I, Kriplani R (2018) 'The role of natural factors (part 1): addressing on mechanism of different types of ENSO, related teleconnections and solar influence'. Theor Appl Climatol pp 1-12. https://doi.org/ $10.1007 / \mathrm{s} 00704-018-2597-\mathrm{z}$

Roy I, Tedeschi RG (2016) Influence of ENSO on regional ISM precipitation - local atmospheric influences or remote influence from Pacific. Atmosphere 7:25. https://doi.org/10.3390/atmos7020025

Roy I, Tedeschi RG, Collins M (2017) ENSO teleconnections to the Indian summer monsoon in observations and models. Int $\mathrm{J}$ Climatol 37(4):1794-1813. https://doi.org/10.1002/joc.4811

Roy I, Gagnon AS, Siingh D (2018) Evaluating ENSO teleconnections using observations and CMIP5 models. Theoretical and Applied Climatology. https://doi.org/10.1007/s00704-018-2536-z

Sato M, Hansen JE, McCormick MP, Pollack JB (1993) Stratospheric aerosol optical depths $(1850$ - 1990). J Geophys Res, $98987-$ 22(994):22

Smith TM, Reynolds RM (2004) Improved extended reconstruction of SST (1854-1997). J Clim 17:2466-2477 
Stenchikov G, Delworth TL, Ramaswamy V, Stouffer RJ, Wittenberg A, Zeng F (2009) Volcanic signals in oceans. J Geophysical Research 114:D16104. https://doi.org/10.1029/2008JD011673

Thompson DWJ, Wallace JM (2000) Annular modes in the extratropical circulation. Part I: month-to-month variability J Clim. 13:1000 1016

Thompson et al (2010) An abrupt drop in Northern Hemisphere sea surface temperature around 1970, Nature, 467:444-447

Trenberth KE, Hoar TJ (1996) The 1990-1995 El Niño-southern oscillation event: longest on record. Geophys Res Lett 23: $57-60$

Trenberth KE, Caron JM, Stepaniak DP, Worley S (2002) Evolution of El Niño-southern oscillation and global atmospheric surface temperatures. J Geophys Res 107(D8):4065. https://doi.org/10.1029/ 2000JD000298

Turner AG, Annamalai H (2012) Climate change and the south Asian summer monsoon. Nat Clim Chang 2:587-595

Vecchi GA, Soden BJ (2007) Global warming and the weakening of the tropical circulation. J Clim 20:4316-4340

Weng H, Ashok K, Behera SK, Rao SA, Yamagata T (2007) Impacts of recent El Niño Modoki on dry/wet conditions in the Pacific rim during boreal summer. Clim Dyn 29:113-129. https://doi.org/10. 1007/s00382-007-0234-0
Xavier PK, Marzin C, Goswami, BN (2007) An objective definition of the Indian summer monsoon season and a new perspective on the ENSOmonsoon relationship. Q. J. R. Meteorol Soc 133:749-764

Yeh S, Kug J, Dewitte B, Kwon M, Kirtman B, Jin F (2009) El Niño in a changing climate. Nature 461:511-514

Yim SY, Wang B, Liu J, Wu Z (2013) A comparison of regional monsoon variability using monsoon indices. Clim Dyn 2013:1423-1437. https://doi.org/10.1007/s00382-013-1956-9

$\mathrm{Yu}, \mathrm{Kim}$ (2010) Identification of central-Pacific and eastern-Pacific types of ENSO in CMIP3 models. Geophysical Research Letters 37:15. https://doi.org/10.1029/2010GL044082

Zhang D, McPhaden MJ (2006) Decadal variability of the shallow Pacific meridional overturning circulation: relation to tropical sea surface temperatures in observations and climate change models. Ocean Model 15(3-4):250-273

Publisher's note Springer Nature remains neutral with regard to jurisdictional claims in published maps and institutional affiliations. 